\title{
Uma abordagem histórica da reflexão e da refração da luz
}

A historical approach to reflection and refraction of light

\author{
Daniel Ortega ${ }^{* 1}$, Breno Arsioli Moura \\ ${ }^{1}$ Universidade Federal do ABC, Santo André, SP, Brasil
}

Recebido em 16 de Maio de 2019. Revisado em 15 de Julho de 2019. Aceito em 22 de Julho de 2019

\begin{abstract}
Este trabalho apresenta uma proposta de ensino dos fenômenos da reflexão e da refração da luz a partir de uma abordagem histórica da ciência. Essa abordagem histórica é fundamentada em cinco pilares: estudos em história da óptica, a experimentação investigativa, os três momentos pedagógicos, a leitura contextualizada de fontes primárias e a natureza da ciência. Nossa intenção é oferecer alternativas ao ensino essencialmente geométrico da óptica, apresentando uma proposta diversificada e dinâmica, que trabalhe adequadamente conceitos científicos, ao mesmo tempo incluindo uma fundamentação histórica não distorcida e superficial.
\end{abstract}

Palavras-chave: reflexão, refração, óptica, história da ciência, natureza da ciência.

This paper presents a proposal to teach reflection and refraction of light through a historical approach. This historical approach is based on five pillars: studies on the history of optics, the investigative experimentation, the three pedagogical moments, the contextual reading of primary sources and nature of science. Our aim is to offer alternatives to the traditional geometric approach of optics in science teaching, presenting a diverse and dynamic proposal that discuss, simultaneously, scientific concepts and its historical foundations, in an adequate, non-distorted and non-superficial manner.

Keywords: reflection, refraction, optics, history of science, nature of science.

\section{Introdução}

A inserção de abordagens históricas em situações de ensino tem se mostrado nas últimas décadas como um caminho possível para transformar as aulas de ciências. Educadores e historiadores apontam que estudar elementos da história da ciência contribui para facilitar a aprendizagem de conceitos científicos, incrementar a cultura geral do aluno, compreender as diversas nuances da construção da ciência e de sua natureza, entre outros pontos [1-4].

No entanto, pesquisadores da área salientam que a mera inclusão de conteúdos históricos em sala de aula não é garantia de uma mudança do viés tradicional de ensino, concentrado na discussão dos produtos da ciência, e não nos processos. Autores como Höttecke e Silva [5] apontam como essa tarefa não é simples e esbarra em questões que vão desde a própria visão do que é ciência e por quem ela é feita, até questões estruturais, como espaço nos currículos. A complexidade dos temas históricos tratados também são barreiras significativas, uma vez que não basta simplesmente selecionar qual história da ciência deve ser incluída, mas deve-se pensar se ela está adequada à formação daquele que a lecionará e a estudará em sala de aula [6]. Dessa forma, embora a importância da história da ciência para o ensino seja um consenso

*Endereço de correspondência: breno.moura@ufabc.edu.br razoavelmente bem estabelecido, parece um desafio atual a questão do como incorporá-la [7].

Neste artigo, buscamos apresentar subsídios para promover o como incorporar a história da ciência no ensino. Discutimos uma proposta de duas atividades com abordagem histórica dos fenômenos da reflexão e da refração da luz para o ensino médio, baseada no estudo de fontes primárias de René Descartes (1596-1650), Christiaan Huygens (1629-1695) e Isaac Newton (1642-1727) ${ }^{1}$ A proposta sustenta-se em cinco pilares: os estudos especializados sobre esses filósofos naturais [8] $?^{2}$ a experimentação investigativa $[9], 3$ os três momentos pedagógicos

\footnotetext{
1 A escolha desses três filósofos naturais para protagonizarem a proposta apresentada neste trabalho deu-se por três motivos: (1) os três desenvolveram ideias fundamentais para o desenvolvimento da óptica, inclusive para a refração e a reflexão; (2) suas ideias coexistiram entre os demais filósofos naturais da época e foram utilizadas por diferentes grupos e em diferentes momentos para entender a natureza e o comportamento da luz; e (3) grande parte de seus escritos em óptica foi traduzida para o português brasileiro, prescindindo a consulta aos originais em francês e em inglês. Dessa forma, o leitor poderá acessar diretamente os trechos citados na seção 3, complementando o recorte apresentado neste artigo e aprimorando seus conhecimentos a respeito dos três filósofos naturais e da óptica no século XVII.

2 O trabalho de Darrigol [8] não é o único estudo sobre os três filósofos naturais. Porém, como se trata de um trabalho que se baseia em outras análises específicas sobre os autores e sobre os períodos em que escreveram, acreditamos que ele é uma boa referência de síntese do tema em questão.

3 O artigo de Sasseron [9] apresenta uma coletânea de artigos relacionados ao tema.
} 
[10], a leitura contextualizada de fontes primárias [11] e a natureza da ciência [4]. Cada um deles será detalhado nas seções a seguir. Em suma, a proposta busca, a partir da leitura contextualizada dos escritos de Descartes, Huygens e Newton, e com o aporte da experimentação investigativa e dos três momentos pedagógicos, trabalhar dois aspectos da natureza da ciência $(\mathrm{NdC})$ : a contínua transformação do conhecimento científico e a impossibilidade de um modelo científico ser o único modo de explicar um fenômeno. Ela é um recorte e uma adaptação de um conjunto maior de atividades, que pode ser consultado em Ortega [12].

Além de se inserir na perspectiva de como introduzir conteúdos históricos em sala de aula, este artigo busca subsidiar novas estratégias para o ensino de uma área frequentemente marginalizada da física no ensino médio, a óptica. Não é novidade que o ensino dessa área é geralmente relegado a pouco tempo nas aulas e pouco espaço nos livros e demais materiais didáticos. A óptica ensinada é essencialmente geométrica, em que são enfatizados o desenho dos raios de luz, o funcionamento de lentes e outros aparatos ópticos, relações matemáticas entre o objeto e a imagem formada etc. [13-15]. Raramente a natureza física da luz é discutida, tampouco questões históricas, exceto pela famosa - e superestimada - disputa entre as concepções ondulatória e corpuscular [16]. Este artigo busca suprir essas lacunas, apresentando, portanto, aspectos de estudos recentes acerca da óptica e subsídios para que sejam implementados em contextos de ensino.

\section{Os pilares da proposta}

Nessa seção, apresentamos os elementos principais dos pilares que fundamentam nossa proposta de abordagem histórica da refração e da reflexão da luz por meio de fontes primárias. Esses pilares envolvem conceitos e conhecimentos bastante abrangentes, e não é nosso objetivo esgotar a discussão sobre eles. Os pontos desenvolvidos nesta seção foram considerados suficientes para fundamentar a proposta, mas o leitor é livre para aprofundar seu conhecimento, a partir da consulta dos diversos trabalhos referenciados.

\subsection{As concepções sobre luz de Descartes, Huygens e Newton: um resgate a partir da história da óptica}

Até o meio do século XX, os estudos sobre a história da óptica dos períodos de Descartes, Huygens e Newton era significativamente diferente da atual. De maneira geral, havia uma concepção de que ocorrera um grande debate entre concepções para a luz, com Newton e Huygens como protagonistas, sendo as ideias do primeiro vitoriosas. Descartes havia desempenhado um papel importante, principalmente por sua influência sobre Huygens e sobre uma geração de pensadores franceses e de alguns outros países, mesmo pertencendo a um outro momento da his- tória 4 Estudos especializados publicados da década de 1970 em diante têm desconstruído essa narrativa e mostrado um cenário heterogêneo e dinâmico, com uma série de aspectos culturais, sociais, pessoais e científicos no desenvolvimento dos conceitos sobre luz [16-18]. Especificamente sobre os três filósofos naturais, historiadores têm mostrado como suas concepções são repletas de nuances que evidenciam a complexidade de seus pensamentos a respeito dos fenômenos luminosos [19-22]. Abordaremos a seguir tópicos relevantes para o propósito deste artigo relacionados aos estudos em óptica de Descartes, Huygens e Newton. A análise de suas explicações sobre a refração e a reflexão da luz, porém, será apresentada na seção 3, por uma questão de conveniência e para evitar repetições.

O século XVII ficou marcado como um período de intenso desenvolvimento na óptica. Nesse século, foram inventadas as primeiras lunetas e microscópios, instrumentos importantes nos trabalhos de filósofos naturais como Galileu Galilei (1564-1642) e Robert Hooke (16351703). Também ocorreu nesse século a descoberta de novos fenômenos ópticos, tais como a difração - por Francesco Grimaldi (1618-1663) - e a dupla refração, por Erasmus Bartholinus (1625-1698). Eventos como esses estimularam a pesquisa sobre a natureza e comportamento da luz, o funcionamento do olho e vários outros fenômenos importantes, envolvendo cores, como o arco-íris, a dispersão da luz após sua passagem por um prisma, os anéis coloridos em películas finas, entre outros [8].

Nesse contexto, destacaram-se os estudos de Descartes sobre a luz. Apesar de sua primeira publicação ter sido feita apenas em 1637, com o Discurso do método, seguido de três tratados científicos, desde cedo ele demonstrou interesse pela óptica. Dentre as influências sobre Descartes estavam os manuais escolares da primeira metade do século XVII, que continham comentários de textos aristotélicos. Seu contato com esses manuais iniciou-se em meados de 1610, quando começou os estudos no Collége La Flèche. Outras influências sofridas por Descartes estão nas pesquisas em óptica de seus antecessores e coetâneos, como Galileu e Johannes Kepler (1571-1630) [23].

Embora Descartes rejeitasse o atomismo, não acreditando na existência dos átomos e nem dos espaços vazios, sua filosofia natural guardou algumas semelhanças com essa proposta. Ele tentou explicar todos os fenômenos observáveis por meio dos movimentos invisíveis das partículas que constituem a matéria [22]. Em O mundo ou tratado da luz (1664) 5 ele apresentou uma concepção de matéria, dividindo-a em três elementos. O primeiro elemento, que constituía os corpos luminosos, seria o mais sutil e mais penetrante de todos, sendo suas partes as mais diminutas e que mais rápido se moviam. Descar-

\footnotetext{
4 Descartes produziu seus trabalhos no início do século XVII, atuando na Holanda e na França. Newton e Huygens viveram o contexto do final do século XVII, o primeiro na Grã-Bretanha e o segundo a maior parte de sua vida na França.

5 Essa obra foi publicada postumamente.
} 
tes imaginou que as partículas desse primeiro elemento poderiam ser divididas e moldadas em qualquer forma, de modo que não havia lugar que elas não pudessem penetrar e preencher completamente. O segundo elemento, que existia nos corpos transparentes e preenchia todo espaço celeste, seria constituído de partículas redondas e de tamanho médio. Já o terceiro elemento, que formava os corpos macroscópicos opacos, seria constituído de partículas maiores, irregulares e com mobilidade reduzida.

Até o período em que as obras de Descartes foram publicadas, não existia uma estimativa precisa da velocidade da luz e a maioria dos filósofos naturais acreditava que ela se propagava de forma instantânea, incluindo ele próprio [22]. Para ele, não existia objeto que pudesse se movimentar com velocidade infinita, pois assim ele seria onipresente. Apoiado nesses argumentos, Descartes rejeitou a materialidade da luz afirmando que ela não poderia ser um objeto, dando-a o caráter de tendência ao movimento para explicar sua propagação instantânea. Descartes entendia a luz como uma espécie de pressão que era transmitida ao longo da matéria. Ele utilizou a analogia de um cego com uma bengala para justificar sua ideia, pois, assim como as vibrações seriam transmitidas instantaneamente através da bengala até a mão do cego, a luz assim seria pela matéria. No que tange os fenômenos da reflexão e refração, ele comparou o movimento da luz ao movimento de uma bola de têni: ${ }^{6}$ disparada por uma raquete para formalizar as leis, pois para ele a tendência ao movimento seguia as mesmas leis que o próprio movimento dos corpos.

No que diz respeito ao estudo das cores, Descartes acreditava que elas seriam modificações da luz branca simples e homogênea. Para explicar as cores produzidas no arco-íris, ele inseriu um novo elemento, a rotação das partículas. Dessa forma, ele imaginava que as partículas do segundo elemento se propagavam na mesma direção e sentido da luz e possuíam um movimento de rotação, responsável por definir a cor dessa luz. Assim sendo, quando a luz sofria refração, o movimento de rotação dessas esferas era modificado, de modo que quando ficavam mais aceleradas produziam a cor vermelha e, quando menos aceleradas, produziam o azul. Consequentemente, qualquer cor intermediária era entendida com uma velocidade de rotação intermediária. Descartes também explicou as cores nos corpos opacos, argumentando que a forma, a posição e o movimentos das partículas da superfície desses corpos poderiam alterar a rotação das partículas do segundo elemento, gerando as cores que observamos. A respeito da repercussão de seu trabalho, vale citar as contendas com Thomas Hobbes (1588-1679). Por meio de correspondências, eles debateram sobre a distinção entre movimento e tendência ao movimento, que Descartes admitiu existir, e a distinção entre a refração de um

\footnotetext{
6 O jogo de tênis a que Descartes se referiu não é o que conhecemos hoje, e sim o seu antecessor, conhecido na França como jeu de paume (jogo de palma). Esse nome surgiu porque no início a bola era rebatida com a palma da mão.
}

corpo sólido e a refração de um pulso de luz, o que ele nunca fez e nem compreendeu [19, p. 155].

Dessa forma, quando Huygens e Newton começaram a trabalhar com óptica, a compreensão dos fenômenos luminosos era um pouco mais abrangente e, por conta de ideias como as de Descartes, a natureza da luz parecia ter sido explicada. Porém, o assunto não se esgotou. Registros da Royal Society, uma das primeiras e mais importantes sociedades de filosofia natural dos séculos XVII e XVIII, mostram como a óptica foi assunto constante nas reuniões entre seus membros nesse período [24].

Os trabalhos em óptica produzidos por Huygens tiveram grande influência dos escritos anteriores de Descartes. Huygens pensou em uma concepção vibraciona $7^{7}$ para a luz, mas, ao contrário de Descartes, não considerou as cores em sua mais conhecida obra em óptica, o Tratado sobre a luz (1690). Esse texto, finalizado doze anos antes de sua publicação, foi dividido em seis capítulos, cada um abordando um assunto específico: (1) propagação retilínea da luz, (2) reflexão, (3) refração, (4) refração no ar, (5) dupla refração e (6) a forma dos corpos para produzir a refração e a reflexão. Postumamente, foi publicada sua Dioptrica, uma série de textos que abordaram aspectos da óptica geométrica [16, p. 120]. Ao contrário do que geralmente se acredita, o Tratado não foi tão popular entre os filósofos naturais posteriores a Huygens [18, p. $56]$.

Ao ver de Shapiro [19], Huygens nega de forma bem explícita a periodicidade das ondas de luz, por conta da analogia que fez com o som. No entanto, o historiador sugere que ele teria reconhecido que sua teoria se aplicava igualmente a pulsos e ondas periódicas e acreditava que a admissão dessa periodicidade seria uma restrição não justificada. Ao longo do Tratado Sobre a Luz, Huygens demonstrou grande capacidade inventiva e habilidade para lidar com a geometria que fundamentava esse modelo vibracional. Segundo ele, seu propósito era esclarecer algumas verdades obtidas da experimentação - tais como a propagação retilínea dos raios luminosos, a igualdade dos ângulos de incidência e reflexão, a regra dos senos na refração - a partir de "razões mais claras e verossímeis" [25].

Para justificar seu modelo, Huygens utilizou alguns argumentos que, segundo ele, descontruíam a concepção corpuscular da luz, tais como sua velocidade, seu espalhamento por todos os lados e o fato dos raios luminosos se cruzarem sem se atrapalhar. Para ele, seria absurdo um corpúsculo se movimentar com velocidade tão grande. Em segundo lugar, caso a luz fosse um objeto se deslocando do corpo até o olho do observador, como uma

\footnotetext{
7 Apesar de Huygens afirmar que a luz é uma onda, o conceito de onda utilizado por ele não é o mesmo que adotamos hoje, pois suas ideias não englobam propriedades atualmente vistas como características das ondas, tais como comprimento de onda e frequência. Assim como Cantor [17], classificamos sua teoria como vibracional, e não ondulatória. No entanto, ao longo do texto, manteremos os termos na forma que foram traduzidos na edição em português do Tratado.
} 
flecha, seria impossível essa flecha se espalhar por todos os lados, ou seja, o fato de uma pequena chama espalhar luz por um ambiente não teria explicação. Por fim, ainda mais improvável seriam as partículas de luz não se chocarem umas com as outras, não gerando nenhuma confusão perceptível em suas propagações.

Ao considerar a luz uma vibração sendo propagada por um meio material, Huygens recorreu ao conceito de éter. Segundo ele, a matéria etérea estava presente na essência de tudo e seria composta de pequenos corpúsculos de dureza e capacidade de restituição perfeita, pelos quais o movimento vibracional da luz seria transmitido, de forma análoga ao movimento de uma esfera rígida que se choca com uma fileira de esferas idênticas. Um dos conceitos mais importantes da explicação do filósofo natural holandês é aquele que ficou conhecido como "princípio de Huygens" (Fig. 1). Segundo ele, quando a vibração de luz originada em um ponto do corpo luminoso se propagava pela matéria, ela faria com que as partículas dessa matéria gerassem ondas secundárias, que acabavam reforçando essa vibração inicial. Isso, de acordo com ele, faria com que os efeitos dessa vibração se estendessem temporalmente, o que explicaria porque a luz do Sol e das estrelas, por exemplo, conseguia chegar à Terra, mesmo estando a grandes distâncias dela. Até hoje, esse conceito é utilizado na abordagem geométrica da óptica.

No caso de Newton, seus primeiros estudos em óptica foram realizados por volta de 1664, quando ainda era estudante na Universidade de Cambridge. Anotações dessas incursões iniciais foram feitas em um caderno que ele intitulou de Quaestiones quaedam philosophicae (Algumas questões filosóficas). Nele, escreveu sobre vários tópicos, dentre eles: "Sobre as cores", "Sobre a visão", "Sobre a luz" etc. Nessa época, Newton conheceu os textos de Walter Charleton (1619-1707) e Robert Boyle (16271691). Os dois autores o teriam influenciado a adotar uma concepção corpuscular para a luz [22, p. 4202-3]. Em algum momento, leu também textos de Descartes e sabe-se que fez anotações da Micrographia (1665) de Hooke [26].

Nesses estudos iniciais, é possível perceber que Newton tende a negar a teoria vibracional e adotar uma teoria corpuscular para a natureza da luz. Em um dos tópicos de seu caderno de anotações, "Sobre a luz", ele registrou algumas críticas às ideias cartesianas. Conforme já mencionado, Descartes supunha que a luz seria uma pressão ou tendência ao movimento. Newton argumentou que "a luz não pode ocorrer por pressão, pois, nesse caso, enxergaríamos tão bem ou melhor à noite do que de dia". Um dos fundamentos dessa afirmação foi que, caso assim ocorresse, não poderia existir a refração da luz, pois segundo Newton, "a mesma matéria não pode exercer pressão em dois sentidos" [27]. É fundamental ressaltar, contudo, que apesar de ter criticado concepções vibracionais, Newton não defendeu abertamente uma concepção corpuscular, preferindo abster-se de discutir a natureza da luz, exceto em partes explicitamente especulativas de seus escritos, por exemplo, nas "Questões" do Óptica [16, $22,28]$.

Em 1672, Newton publicou o artigo "Nova teoria sobre luz e cores", que tornou algumas de suas ideias sobre a luz conhecidas [29]. O texto tratou da refrangibilidade e da composição da luz branca. Em seus famosos experimentos com prismas, Newton defendeu a ideia de que a luz branca seria uma mistura heterogênea de raios coloridos e que o prisma apenas os separava. Na época, o artigo provocou muitas críticas e comentários de filósofos naturais importantes, como Hooke e Huygens, pois sua proposta contrapunha a ideia de que a luz era uma substância simples e homogênea e que as cores eram qualidades adquiridas, aceita por grande parte dos pensadores.

Em 1704, Newton publicou sua obra final sobre a luz e as cores, o Óptica. A obra foi dividida em três livros, que também estão divididos em partes. O Livro I trata da natureza heterogênea dos raios de luz e das cores dos objetos, com forte viés experimental. O Livro II aborda
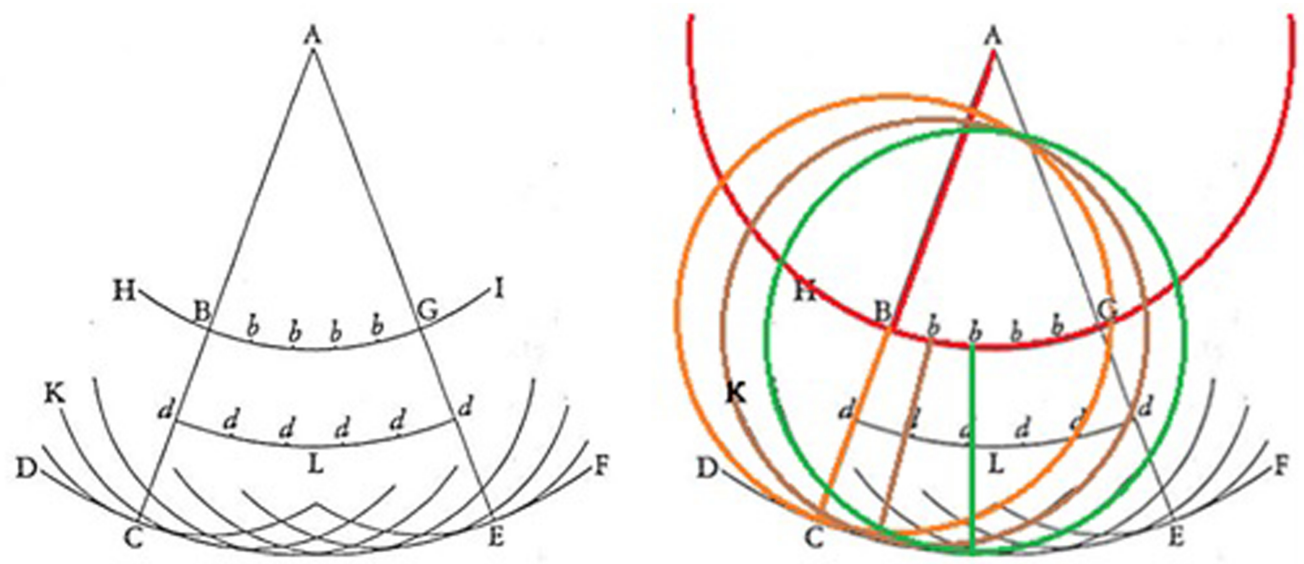

Figura 1: A figura representa os pontos que o arco BG perturba criando novas frentes de onda, com centro neles, compondo uma nova frente de onda com uma tangente em comum, o arco CE. Os círculos coloridos foram inseridos para facilitar a visualização [25, p. 23]. 
as cores dos corpos naturais e o fenômeno atualmente denominado de "anéis de Newton". Por fim, no Livro III, Newton tratou da difração da luz - chamada por ele de inflexão -, e incluiu as "Questões", a parte explicitamente especulativa do Óptica. Nela, ele discutiu mais livremente temas controversos, como a natureza corpuscular da luz, a composição da matéria, o papel do éter nos fenômenos naturais etc., sem, contudo, se comprometer com nenhum deles.

\subsection{Experimentação investigativa}

Em um modelo tradicional de ensino, as aulas costumam ser baseadas em exposição de conteúdo, memorização e aplicação de fórmulas e resolução de exercícios padrão, tornando-as desinteressantes, como apontam diversas pesquisas na área $[30] 8^{8}$ Com o intuito de fundamentar nossa proposta em bases diferentes e que fomentem um processo de ensino e aprendizagem mais crítico e transformador, optamos pela Experimentação Investigativa (EI). O uso da experimentação é uma forma de fazer com que o aluno participe ativamente desse processo, sendo capaz de tecer relações entre as observações e dados tomados no experimento, de modo a estabelecer uma explicação causal acerca dos resultados de suas ações e/ou interações [31].

Segundo Guedes [32], a EI tem como objetivo orientar os estudantes a pensar, debater, justificar ideias e também saber aplicar o conhecimento adquirido em diversas situações. Partindo desses pressupostos, para a experimentação ser considerada investigativa, ela deve promover no aluno habilidades como curiosidade, iniciativa, criticidade, poder argumentativo, entre outras. De acordo com Francisco Jr. [33], a EI deve se contrapor à educação bancária [34], na qual o conhecimento é transferido de forma acrítica e apolítica, como uma doação daquele que sabe mais para aquele que sabe menos. A EI deve incentivar uma busca incessante pelo conhecimento, despertando nos alunos um espírito crítico e reflexivo, tornando-os sujeitos de sua aprendizagem, à medida que são capazes de formular hipóteses e discutir sobre o tema.

Na literatura, podemos encontrar diversos trabalhos ancorados na EI. Por exemplo, Barrelo Jr. [35] adaptou uma sequência de ensino elaborado no Laboratório de Pesquisa em Ensino de Física (LAPEF), da USP, modificando as atividades para o Ensino por Investigação $9^{9}$ Nesse trabalho, o autor pesquisou como se desenvolvia o processo argumentativo dos alunos sobre o conceito de fóton e se eram capazes de relacionar o comportamento da luz com as interpretações da mecânica quântica. Para

\footnotetext{
8 Consideramos o trabalho de Moreira [30] uma síntese do que se tem feito na pesquisa em Ensino de Física. Seria impraticável citar todos os trabalhos que já apontaram a ineficácia do ensino tradicional.

9 O Ensino por Investigação pode ser definido como uma forma de ensinar o conteúdo programático por meio de condições que permitam que os alunos possuam um papel mais ativo na própria aprendizagem. A Experimentação Investigativa surge como uma proposta que se encaixa nesse modelo de ensino.
}

isso, aplicou um conjunto de atividades experimentais investigativas que envolveram a montagem e a exploração dos equipamentos e o uso de uma simulação de computador para a idealização do experimento, exigindo dos alunos uma postura mais ativa. Essa sequência foi aplicada em turmas do terceiro ano do ensino médio e como método de avaliação foram analisadas as discussões e os registros finais dos alunos.

Outro exemplo é o trabalho de Lopes [36] que elaborou uma sequência de ensino nomeada como "E o elétron? É onda ou partícula?". Seu objetivo foi alfabetizar cientificament 10 alunos de Ensino Médio no contexto da Física Moderna e Contemporânea. Para isso, organizou alguns experimentos conceitualmente vinculados a três textos elaborados por ele próprio. Esses textos são entrevistas com cientistas de grande importância para a Física Moderna. Essas entrevistas foram baseadas no estudo de fontes primárias dos próprios cientistas citados e o intuito dessa prática surgiu na tentativa de tornar o texto mais acessível a alunos de Ensino Médio. Essa sequência foi aplicada em uma escola da rede estadual de São Paulo e os experimentos foram construídos sob o viés da EI, deixando o aluno assumir o controle do processo de aprendizagem, manipulando os experimentos e sendo capaz de estabelecer as relações e os conceitos necessários. Já o uso das fontes primárias em forma de entrevistas, segundo o autor, teve como objetivo subsidiar a base teórica dos alunos e incentivar a leitura dos artigos científicos originais.

O presente artigo caminha em uma perspectiva semelhante aos dois trabalhos citados [35-36] no que diz respeito à prática da Experimentação Investigativa, diferenciandose do primeiro pelo fato de adotar como fundamento conteúdos da história da ciência e do segundo pela forma como as fontes primárias serão trabalhadas.

\subsection{Leitura contextualizada de fontes primárias}

A história da ciência (HC) pode ser utilizada como um excelente recurso pedagógico para ensinar disciplinas de cunho científico, pois com ela é possível tornar as aulas mais desafiadoras e reflexivas, ao passo que ela permite que o aluno compreenda melhor o significado dos conceitos trabalhados em sala de aula. A história da ciência pode contribuir para o entendimento de como o empreendimento científico é humano, pois nele estão inseridos interesses pessoais, éticos, culturais e políticos da comunidade, não sendo isento, como geralmente se acredita [38]. É neste âmbito que surge a ideia da leitura contextualizada de fontes primárias (LC) [39]. Na literatura, podemos encontrar alguns trabalhos que apontam as dificuldades de trabalhar com esse tipo de material, especialmente em questões de linguagem, organização textual, falta de traduções adequadas, entre outros pontos [40-42]

\footnotetext{
10 Em linhas gerais, a alfabetização científica pode ser entendida como a compreensão dos processos pelos quais os conhecimentos científicos são elaborados e validados. Ver Sasseron e Carvalho [37] para uma revisão bibliográfica sobre o tema.
} 
A LC busca minimizar esses problemas, a partir de uma estrutura e conceituação simples. A contextualização envolve relacionar, descrever e explicar o tema, a linguagem e os fundamentos das fontes, ou seja, estudálas de acordo com o contexto em que foram inseridas, de maneira que os leitores tenham subsídios conceituais para compreendê-las. Por exemplo, ao estudarmos uma fonte medieval sobre o movimento, é preciso esclarecer o que era entendido por movimento na época, quais termos eram utilizados e quais seus significados naquele momento - impetus, por exemplo, não era o mesmo que inércia, no sentido atual do termo -, quais as motivações e expectativas de seus autores, as relações entre o conhecimento sobre o mundo natural e a filosofia, entre outros pontos. Dessa forma, a leitura da fonte torna-se mais produtiva e os assuntos nela trabalhados mais fáceis de serem compreendidos por um público não especializado em materiais do tipo ou não familiarizados com a história da ciência.

No caso das LCs apresentadas neste artigo, suas elaborações requereram um estudo detalhado das obras dos cientistas escolhidos - Descartes, Huygens e Newton -, bem como do contexto em que foram produzidas. Assim, foram estudados aspectos da história da óptica até o século XVII, as influências de outros pensadores sobre as ideias dos três cientistas, a relação entre eles, a aceitação e rejeição de suas teorias etc. Não pretendemos, claramente, realizar um estudo novo, mas obter daqueles já existentes as informações necessárias para que fosse possível compreender os assuntos, termos, ideias e experimentos trabalhados por Descartes, Huygens e Newton em suas respectivas obras. Nesse sentido, há diversas obras sobre a óptica nesse período, disponíveis majoritariamente em língua inglesa, como vários dos trabalhos referenciados neste artigo.

Para a proposta apresentada neste artigo, a LC envolve cinco etapas. ${ }^{11}$ A primeira delas é o engajamento. Essa etapa objetiva fazer com o que os alunos mobilizem seus conhecimentos prévios para estudar o conteúdo das fontes. Para os casos tratados neste artigo, o engajamento deu-se em forma de perguntas. A segunda etapa é a discussão dos conhecimentos prévios necessários. Isso implica que devem ser trabalhados os conceitos, ideias e eventos essenciais para que os alunos compreendam o conteúdo das fontes, as motivações de seus autores, suas influências teóricas, entre outros pontos. A terceira etapa é a leitura integral das fontes. Nela, os alunos recebem os trechos selecionados das fontes e a eles é dado tempo para que possam lê-los integralmente. Está abrangido nessa etapa o esclarecimento de possíveis dúvidas acerca de termos e conceitos contidos no material. A quarta etapa é, propriamente, a leitura contextualizada. Para ela, o professor deve esmiuçar o conteúdo das fontes, explicando as principais ideias discutidas, isto é, cada trecho deve ser lido novamente e discutido em detalhes. Essa deve

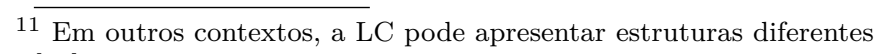
[39]. ser a etapa mais longa de toda a LC. Por fim, a última etapa compreende o debate acerca de questões da natureza da ciência $(N d C)$, em que os aspectos envolvendo a construção do conhecimento científico são trabalhados de maneira mais direta. A discussão dos exemplos de LC nas seções 3.1.2 e 3.2.2 permitirão uma compreensão mais clara desses passos.

\subsection{Natureza da Ciência}

Nas pesquisas acerca da inserção da história da ciência em contextos de ensino, a inclusão, discussão e problematização da natureza da ciência $(\mathrm{NdC})$ têm ocupado um lugar proeminente. Pesquisadores em diferentes vertentes e propostas salientam a importância de ensinar não apenas os conteúdos científicos, mas sobre como eles são produzidos, suas relações com questões externas à ciência, o papel da imaginação, a relação entre teoria e experimento, entre outros pontos [43-45]. Assim como há inúmeros conceitos a respeito do empreendimento científico, também há diversas concepções acerca da própria $\mathrm{NdC}$ [4]. Nesse trabalho, optamos pela visão conhecida como "aspectos consensuais" [46]. Nessa visão, são listados elementos que caracterizam a NdC. Moura [4, p. 34-35], a partir de trabalhos anteriores, sintetizou-os em cinco:

- A ciência é mutável, dinâmica e tem como objetivo buscar explicar os fenômenos naturais;

- Não existe um método científico universal;

- A teoria não é consequência da observação/experimento e vice-versa;

- A ciência é influenciada pelo contexto social, cultural, político etc., no qual ela é construída;

- Os cientistas utilizam imaginação, crenças pessoais, influências externas, entre outros para fazer ciência.

Para a proposta descrita na seção 3 a seguir, trabalhamos com dois aspectos, derivados desses anteriores: a contínua transformação do conhecimento científico e a impossibilidade de um modelo científico ser o único modo de explicar um fenômeno. Entendemos que outros aspectos podem ser trabalhados por meio da proposta apresentada neste artigo, mas consideramos que esses dois são aqueles mais evidentes a partir da abordagem histórica que ela apresenta.

\subsection{Os três momentos pedagógicos}

Os três momentos pedagógicos (3MP) constituem-se de uma dinâmica didático-pedagógica construída a partir de um viés freireano de educação, ou seja, baseada em um processo dialógico entre professor e aluno, permitindo que, ao final do processo, ambos adquiram uma melhor compreensão a respeito do tema estudado. Essa estratégia foi desenvolvida por Delizoicov [10] e até os dias tem sido utilizada e adaptada para diferentes contextos e propósitos [15, 47, 48]. 
Os três momentos pedagógicos são caracterizados por: $1^{\circ}$ Momento (Problematização Inicial) - Nesse momento, são apresentadas situações reais ou questões que fazem parte do cotidiano do aluno. Eles são estimulados a expor o que pensam a respeito das situações abordadas e o professor toma nota de seus conhecimentos prévios. A finalidade desse momento é fazer com que o aluno tente explicar suas interpretações sobre os fenômenos, com base nos conhecimentos que possui, ou perceba que, para compreendê-los, precisará aprender além do que já sabe.

$2^{\circ}$ Momento (Organização do Conhecimento) - Nesse momento, o professor auxilia os alunos com os conhecimentos necessários para a compreensão do fenômeno abordado na situação inicial. É nessa etapa que se desenvolvem definições, conceitos e relações.

$3^{\circ}$ Momento (Aplicação do Conhecimento) - Nesse momento, o professor aborda sistematicamente o conhecimento adquirido pelo aluno para analisar e interpretar tanto as situações iniciais quanto outras relacionadas com o mesmo conhecimento, que possam ser estudadas e explicadas da mesma forma.

Na literatura, podemos encontrar trabalhos que utilizaram os 3MP tanto para inserir conteúdos da história da ciência quanto da óptica. Silva [47], por exemplo, busca estudar a não linearidade da construção do conhecimento científico, propondo a inserção da história da ciência como base para o ensino de ciências. Sua ideia consiste em utilizar essa abordagem já nos anos iniciais do ensino fundamental, com a intenção de acompanhar o desenvolvimento cognitivo das crianças de forma gradativa, e para tal propõe utilizar a experimentação como objeto didático. Para examinar a diferença que a inserção da HC pode trazer na compreensão do fenômeno abordado, em sua proposta, a autora organiza e compara duas turmas, uma que trabalhou apenas com atividades experimentais demonstrativas e outra que utilizou a abordagem histórica. Nas duas aplicações foram utilizados os 3MP como dinâmica de aplicação. No final do trabalho, a autora compreende que há uma grande diferença no enfoque das duas propostas. Enquanto a abordagem tradicional está mais focada na comprovação dos conceitos, a abordagem histórica está focada na construção desses conceitos. Sendo assim, essa última abordagem permite que os alunos se envolvam com os episódios históricos, podendo compreender a não linearidade da ciência.
Albuquerque e colaboradores [15] também utilizam os 3MP em sua proposta, com enfoque na óptica. Tentando ir na contramão do ensino da óptica geométrica atual, eles propõem uma mudança nessa forma tradicional de estudo, buscando algo que se aproxime mais das diretrizes curriculares atuais, privilegiando a explicação dos fenômenos presentes no nosso dia a dia. Nesse trabalho, os autores escolheram separar algumas questões pertinentes ao ramo da óptica e as utilizaram como problematização inicial na proposta, dividindo os alunos em grupos e distribuindo uma questão para cada grupo. Posteriormente, na fase da organização do conhecimento, os estudantes foram convidados a elaborar as seguintes atividades acerca do tema escolhido: produção de um texto explicativo, elaboração de um experimento e preparação de uma apresentação. Por fim, para a aplicação do conhecimento, os autores propõem a apresentação do que foi desenvolvido pelos grupos nas etapas anteriores. Esse é o momento em que os grupos compartilham o texto elaborado e fazem a demonstração do experimento construído. Na conclusão desse trabalho, os autores destacam importância da problematização inicial, pois, segundo eles, essa etapa é capaz de gerar outras discussões além do previsto, e a boa receptividade dos alunos.

\section{A proposta}

Nossa proposta envolve duas atividades sobre reflexão e refração da luz pensadas para serem aplicadas no Ensino Médio. No quadro 1, está descrita a estrutura geral das atividades sugeridas, a partir dos pilares discutidos na seção anterior. Para essa discussão, estipulamos que cada momento tenha duração de duas aulas de 50 minutos, totalizando 1 hora e 40 minutos. O leitor, no entanto, é livre para adaptar a proposta conforme seu próprio contexto. O detalhamento para cada um dos fenômenos considerados neste artigo - reflexão e refração - é dado nas subseções sequentes.

Para essa proposta, foram utilizadas 4 fontes de Descartes, Huygens e Newton. Em relação ao primeiro, foi utilizada A dióptrica [49]. Para Huygens, retiramos trechos do Tratado sobre a luz [25]. Por fim, para Newton, foram utilizados trechos dos Principia [50], seu principal livro de mecânica, publicado pela primeira vez em 1687,

Quadro 1: Estrutura geral das atividades. Os termos em negrito indicam onde os pilares da proposta são trabalhados. Fonte: elaborado pelos autores.

\begin{tabular}{|c|c|c|c|}
\hline & nto Pedagógico (3MP) & Desenvolvimento & Duração \\
\hline 1 & Problematização inicial & $\begin{array}{l}\text { Indagações aos alunos a respeito do fenômeno; } \\
\text { Atividade de experimentação investigativa (EI); } \\
\text { Conclusão do primeiro momento. }\end{array}$ & \multirow{3}{*}{$\begin{array}{l}\text { 1h e } 40 \text { minutos para } \\
\text { cada momento }\end{array}$} \\
\hline 2 & $\begin{array}{l}\text { Organização do conheci- } \\
\text { mento }\end{array}$ & $\begin{array}{l}\text { Esclarecimentos sobre a aula anterior; } \\
\text { Discussão de aspectos históricos da óptica e leitura con- } \\
\text { textualizada de fontes primárias (LC); } \\
\text { Explicação dos modelos propostos no viés dos filósofos naturais. }\end{array}$ & \\
\hline 3 & Aplicação do conhecimento & $\begin{array}{l}\text { Debate acerca de aspectos da natureza da ciência (NdC); } \\
\text { Atividade final. }\end{array}$ & \\
\hline
\end{tabular}


e do Óptica [51], sua obra sobre a luz e as cores, cuja primeira edição é de 1704 .

\subsection{Reflexão da luz}

\subsection{1. $1^{\circ}$ momento: problematização inicial}

Nesse primeiro momento, sugerimos que o professor faça um levantamento acerca dos conhecimentos prévios dos alunos, indagando-os com questões como:

- Na reflexão a luz bate e volta? Isso sempre acontece?

- Se a luz atravessasse o objeto, seria reflexão?

- Existe alguma relação entre o ângulo de incidência e o de reflexão?

- É possivel medir esses ângulos?

Após ouvir as respostas dos alunos, recomendamos que o professor faça uma ampla discussão sobre elas, buscando compreender suas principais concepções a respeito do fenômeno. Essa etapa é muito importante porque é o momento em que o professor terá noção dos conhecimentos prévios da turma, o que permitirá adequar o andamento das atividades.

A etapa seguinte envolve a experimentação investigativa (EI). Sugerimos dividir a sala em pequenos grupos, fornecendo alguns objetos que os possibilitem investigar o fenômeno da reflexão, tais como: lanterna, ponteira laser, espelhos planos, transferidores, réguas, lápis, papel e fita adesiva. Os alunos devem ser instruídos a elaborar um experimento que indique uma possível relação entre o ângulo de incidência e o ângulo de reflexão, utilizando os materiais fornecidos. Por meio de uma folha em branco disponibilizada pelo professor, os alunos devem desenhar as trajetórias dos raios luminosos observadas nos experimentos elaborados. Ao final desse processo, o professor deve recolher a folha. Com isso, ele poderá analisar como os alunos compreenderam o fenômeno da reflexão e se foram capazes de perceber a igualdade entre os ângulos de incidência e reflexão.

\subsection{2. $2^{\circ}$ momento: organização do conhecimento}

No segundo momento, o professor deve tecer comentários sobre a aula anterior e sobre os experimentos realizados pelos alunos. Essa atividade tem como propósito fazer com que os alunos organizem seus conhecimentos acerca do fenômeno da reflexão, baseado nos saberes que já possuem. Em seguida, deve ser iniciada a aplicação da leitura contextualizada de fontes primárias (LC), começando pela etapa do engajamento, por meio da seguinte questão: essa explicação para a reflexão sempre existiu? Com isso, o professor pode verificar o que os alunos já sabem em relação a aspectos históricos da óptica, contribuindo para a tomada de decisões ao longo da aula e eventuais modificações. Posteriormente, na etapa de conhecimentos prévios, o professor deve apresentar alguns dados biográficos e uma síntese das principais obras dos três filósofos naturais protagonistas da proposta: Descartes, Newton e Huygens ${ }^{12}$ Em seguida, na leitura integral, o professor deve distribuir os trechos das fontes primárias, disponíveis nos quadros 2, 3 e 4, fornecendo tempo para leitura. Após o esclarecimento de eventuais dúvidas em relação aos termos e conceitos dos trechos, a leitura contextualizada pode ter início. Conforme descrito na seção 2.3 , nesse momento, o professor detalha cada trecho das fontes, a partir dos subsídios elencados nos quadros 2 . Dessa maneira, os conteúdos das fontes podem se tornar mais compreensíveis aos alunos. Também estão disponíveis algumas ilustrações dos autores - as originais e as adaptadas -, que podem ser utilizadas nessa quarta etapa da LC.

Após a leitura contextualiza, o professor deve prosseguir para a última etapa da LC, o debate acerca de questões da $N d C$. Utilizando os minutos finais da aula para formalizar o entendimento da relação entre os ângulos de incidência e reflexão no viés dos filósofos estudados, o professor

12 Para isso, sugerimos consultar os slides preparados para o minicurso que deu origem à proposta, em Ortega [12].

Quadro 2: Subsídios para a leitura contextualizada (LC) - reflexão - Descartes.

\begin{tabular}{|c|c|}
\hline \multicolumn{2}{|l|}{ Descartes } \\
\hline Dióptrica & \\
\hline Trecho & Subsídios para leitura contextualizada \\
\hline $\begin{array}{l}\text { Pensemos, então, que uma bola, sendo impulsionada de A para B, encontra, } \\
\text { no ponto B, a superfície do chão CBE, que, ao impedi-la de passar mais } \\
\text { adiante, é a causa de seu desvio, e veremos para qual lado [...] } \\
\text { Fonte: }[49, \text { p. } 458]\end{array}$ & $\begin{array}{l}\text { Nesse trecho, Descartes faz uma analogia da reflexão } \\
\text { da luz com uma bola de tênis batendo contra o chão } \\
\text { e subindo novamente. }\end{array}$ \\
\hline $\begin{array}{l}\text { [...] Além do mais, deve-se notar que a determinação de mover-se para } \\
\text { qualquer lado pode, assim como o movimento e geralmente como qualquer } \\
\text { outro tipo de quantidade, ser dividida entre todas as partes das quais } \\
\text { podemos imaginar que ela seja composta; e pode-se facilmente imaginar } \\
\text { que aquela da bola que se move de A para B seja composta por duas outras, } \\
\text { das quais uma a faz descer da linha AF para a linha CE e a outra a faz } \\
\text { ir, ao mesmo tempo, da esquerda AC para a direita FE, de tal modo que } \\
\text { essas duas juntas a conduzem até } B \text {, segundo a linha reta AB. } \\
\text { Fonte: }[49, \text { p. } 458]\end{array}$ & $\begin{array}{l}\text { Com o auxílio de desenhos de Descartes (Fig. 2), } \\
\text { podemos explicar que ele pensa no movimento da } \\
\text { bola de tênis dividido em duas partes: um vertical, } \\
\text { que faz a bola descer da linha AF para a linha CE } \\
\text { (em verde), e um horizontal, que faz se mover da } \\
\text { linha AC para a linha FE (em amarelo). Esses dois } \\
\text { movimentos ocorrem num mesmo intervalo de tempo } \\
\text { e geram um movimento resultante, AB (em verme- } \\
\text { lho). Deve-se reforçar aqui que, embora pareça uma } \\
\text { abordagem vetorial do movimento, ela não existia } \\
\text { da forma como a física atual a considera. }\end{array}$ \\
\hline
\end{tabular}




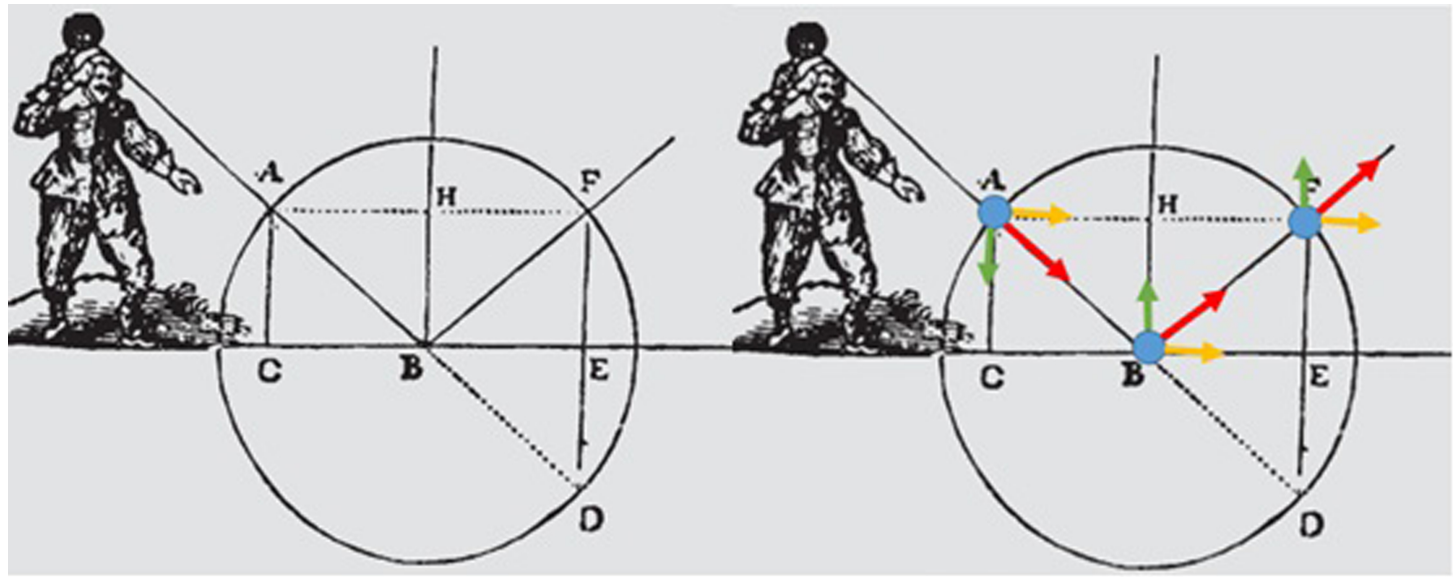

Figura 2: Analogia para explicar a reflexão da luz. À direita, a ilustração adaptada, com indicações dos dois movimentos da bola (vertical e horizontal, em verde e amarelo) e o movimento resultante (em vermelho) [49, p. 458].

Quadro 3: Subsídios para a leitura contextualizada (LC) - reflexão - Huygens.

\begin{tabular}{|c|c|}
\hline \multicolumn{2}{|l|}{ Huygens } \\
\hline Tratado sobre a luz & \\
\hline Trecho & Elementos para leitura contextualizada \\
\hline $\begin{array}{l}\text { Seja uma superfície plana e polida, de algum metal, vidro ou outro corpo, } \\
\text { AB, que inicialmente considerarei como perfeitamente unida [...]. Uma } \\
\text { linha AC, inclinada em relação a AB; representa uma parte de uma onda } \\
\text { de luz, cujo centro esteja tão longe que essa parte AC possa ser considerada } \\
\text { como uma linha reta }[\ldots] \\
O \text { ponto } C \text { da onda AC, em um certo espaço de tempo, terá avançado } \\
\text { até o plano AB no ponto } B \text {, seguindo a reta CB, que se deve imaginar } \\
\text { proveniente do centro luminoso, e que consequentemente é perpendicular a } \\
\text { AC. Ora, nesse mesmo espaço de tempo, o ponto A da mesma onda, que } \\
\text { foi impedido de comunicar seu movimento para além do plano AB, pelo } \\
\text { menos em parte, deve ter continuado seu movimento na matéria que está } \\
\text { acima desse plano, e isso em um alcance igual a CB, produzindo sua onda } \\
\text { esférica particular, segundo o que foi dito acima. Essa onda é representada } \\
\text { aqui pela circunferência SNR, cujo centro é } A \text { e cujo semidiâmetro AN é } \\
\text { igual a CB. } \\
\text { Fonte: }[25, \text { p. 25-26] }\end{array}$ & $\begin{array}{l}\text { Aqui o leitor deve ver na ilustração de Huygens (Fig. } \\
\text { 3) uma frente de onda AC que atinge a superfície } \\
\text { refletora AB. Todas as partes dessa frente de onda } \\
\text { AC se propagam com a mesma velocidade. Dessa } \\
\text { maneira, em um determinado intervalo de tempo, to- } \\
\text { dos os pontos da frente de onda AC terão percorrido } \\
\text { um mesmo espaço. Assim, quando o ponto C chegar } \\
\text { em B, o ponto A terá atingindo o ponto G. Porém, } \\
\text { como há a superfície refletora AB, quando o ponto } \\
\text { A a atinge, será criada uma perturbação, uma onda } \\
\text { esférica particular com centro em A, que se propa- } \\
\text { gará até N formando a onda SNR, cuja distância de } \\
\text { A é igual a AN, que é igual a AG e a CB. } \\
\text { Os triângulos ACB e ANB são semelhantes, de onde } \\
\text { pode ser demonstrada a igualdade dos ângulos de } \\
\text { incidência e reflexão, corroborando a conhecida lei } \\
\text { da reflexão. }\end{array}$ \\
\hline
\end{tabular}
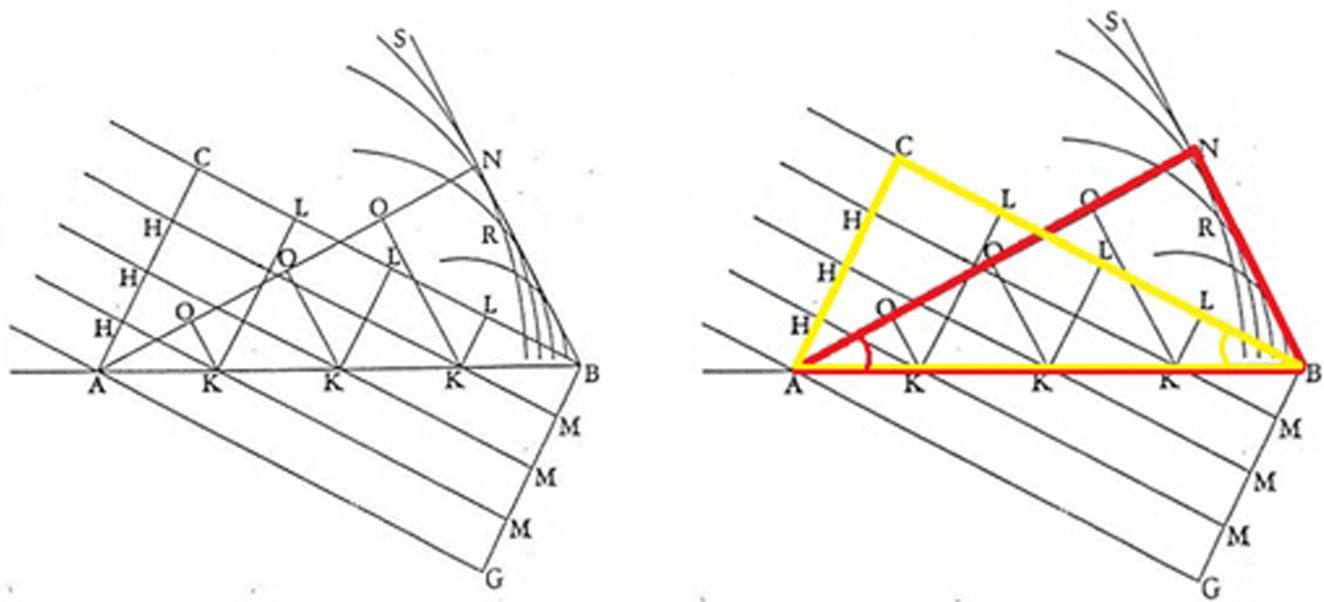

Figura 3: Representação da onda refletida. À direita, a ilustração adaptada, com indicações dos dois triângulos congruentes, que indicam a igualdade entre os senos de incidência e reflexão [25, p. 25]. 
Quadro 4: Subsídios para a leitura contextualizada (LC) - reflexão - Newton.

\begin{tabular}{lcc}
\hline & Newton & \multicolumn{1}{c}{ Óptica } \\
\hline Trecho & Elementos para leitura contextualizada \\
\hline Definição III & Nessas definições, Newton apresenta argumen- \\
A reflexibilidade dos raios é sua tendência a ser refletidos ou a voltar para o & tos e termos bem semelhantes aos que são apli- \\
mesmo meio, vindas de qualquer outro meio sobre cuja superfície incidem. E os & cados até hoje na óptica geométrica. Percebe-se \\
raios que voltam com maior ou menor facilidade são os raios mais ou menos & que, nesse trecho, Newton apenas define o que \\
reflexíveis. & é a reflexão, sem tratar de suas causas.
\end{tabular}

Definição $I V$

Ângulo de incidência é o ângulo em que a reta descrita pelo raio incidente forma com a perpendicular à superfície refletora ou refratora no ponto de incidência. Definição $V$

Angulo de reflexão ou refração é o ângulo em que a reta descrita pelo raio refletido ou refratado forma com a perpendicular à superfície refletora ou refratora no ponto de incidência.

Fonte: [51, p. 40-41]

Proposição 8

A causa da reflexão não é o choque da luz com as partes sólidas ou impenetráveis dos corpos, como geralmente se acredita.

$$
\text { Fonte: [51, p. 199] }
$$

\section{Proposição 8 (cont.)}

Finalmente, se os raios de luz refletidos se chocassem com as partes sólidas dos corpos suas reflexões nos corpos polidos não poderiam ser tão regulares como são. Pois polindo-se vidro com areia, potéia ou trípole não é imaginável que essas substâncias possam, ao raspar e friccionar o vidro, efetuar em todas as suas particulas menores um polimento acurado, de modo que todas as suas superficies sejam verdadeiramente planas ou verdadeiramente esféricas e pareçam todas da mesma forma, de maneira a comporem, juntas, uma substância uniforme. Quanto menores forem as partículas dessa substância, menores serão as ranhuras pelas quais elas desgastam e riscam o vidro continuamente até ele ficar polido; porém, como elas nunca são tão pequenas, não podem desgastar o vidro de outra forma senão raspando-o, riscando-o e quebrando as protuberâncias; portanto não o podem polir de outra forma senão trazendo a sua aspereza a um grau muito pequeno, de forma que as ranhuras e desgastes da superficie se tornem muito pequenos para serem visíveis. Assim, se a luz fosse refletida ao chocar-se com as partes sólidas do vidro, ela seria tão espalhada pelo vidro mais polido quanto pelo mais áspero. Resta pois o problema de saber como o vidro polido por substâncias abrasivas pode refletir a luz tão regularmente quanto o faz. E esse problema dificilmente será resolvido de outra forma que não dizendo-se que a reflexão de um raio é efetuada, não por um ponto único do corpo refletor, mas por algum poder do corpo que está espalhado uniformemente por toda sua superfície e pela qual ele age sobre o raio sem contato imediato.

Fonte: [51, p. 200-201]

\begin{tabular}{|c|c|}
\hline \multicolumn{2}{|l|}{ Principia } \\
\hline Trecho & Elementos para leitura contextualizada \\
\hline Proposição XCVI. Teorema L & Nos Principia, Newton já tinha discutido como \\
\hline O mesmo sendo posto, e sendo mais rápido o movimento antes da incidência do & as reflexões de corpos materiais (como descrito \\
\hline que após, afirmo que, se a linha de incidência for inclinada continuamente, o & na Proposição XCVI) eram semelhantes às re- \\
\hline $\begin{array}{l}\text { corpo finalmente será refletido, e o ângulo de reflexão será igual ao ângulo de } \\
\text { incidência. }\end{array}$ & flexões de raios de luz (Fig. 4). \\
\hline Escólio & \\
\hline Essas atrações guardam grande semelhança com as reflexões e refrações da luz & \\
\hline realizadas em uma dada razão das secantes, como foi descoberto por Snell; & \\
\hline $\begin{array}{l}\text { e, consequentemente, em uma dada razão dos senos, como foi mostrado por } \\
\text { Descartes. }\end{array}$ & \\
\hline Fonte: $[50$, p. 293] & \\
\hline
\end{tabular}

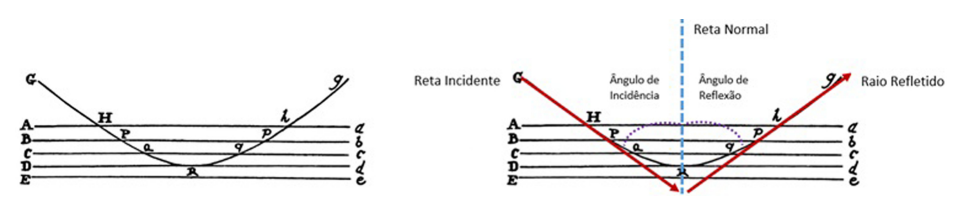

Figura 4: Representação da reflexão de um corpo sólido. À direita, a figura adaptada, com uma alusão sobre como ela também poderia descrever a reflexão de um raio de luz [50, p. 292]. 
destaca as peculiaridades de cada modelo e mostra que mesmo com ideias diferentes, foram capazes de atender a um mesmo propósito, explicar a reflexão da luz.

\subsection{3. $3^{\circ}$ momento: aplicação do conhecimento}

No terceiro momento, o professor deve criar e mediar um debate em sala de aula, a fim de discutir os modelos explicativos estudados na aula anterior, levando em consideração a importância que cada um deles teve no processo de construção do conhecimento científico. O intuito desse momento é reforçar a discussão da última etapa da LC, trabalhando sobre os aspectos da $\mathrm{NdC}$ descritos anteriormente: a contínua transformação do conhecimento científico e a impossibilidade de um modelo científico ser o único modo de explicar um fenômeno.

Uma primeira discussão pode enfatizar as diferentes explicações para um mesmo fenômeno. Descartes, Huygens e Newton escreveram seus trabalhos em momentos distintos e apresentaram ideias divergentes. O professor pode ressaltar como a natureza não oferece evidências que permitem apenas uma explicação e como cada pensador, filósofo natural ou cientista pode interpretar de acordo com seus conhecimentos prévios e expectativas.

Além disso, podem ser debatidos os diferentes modos de um mesmo autor explicar o fenômeno, como foi o caso de Newton. Nos Principia, por exemplo, ele menciona explicitamente que pode haver uma analogia entre o comportamento dos corpos e o da luz.No início de seu Óptica, ele deduziu a igualdade entre os senos de incidência e reflexão sem se preocupar muito com a natureza do fenômeno, trabalhando com a obviedade retirada da observação. No entanto, mais à frente ele considerou a causa do fenômeno, o atribuindo a algum poder entre a luz e os corpos. Isso sugere como Newton, dependendo do contexto, abordou o fenômeno mais do ponto de vista geométrico para, em outro, discutir suas causas. Após esse debate, deve ser proposta uma atividade final para os alunos aplicarem o conhecimento. Segue um exemplo de atividade.

$\underline{\text { Atividade final }}$

1. Responda às questões:

a) Descreva resumidamente como Descartes, Huygens e Newton explicam a reflexão da luz. Dê bastante ênfase à geometria utilizada por cada um deles.

b) Olhando para os três modelos, é possível perceber que o conhecimento científico não é estático e nem convergente? Explique.

2. Pesquise e construa um periscópio. Agora utilize seus conhecimentos acerca da reflexão da luz para explicar o funcionamento desse instrumento. Faça uso de esquemas e textos.

\subsection{Refração da luz 13}

\subsection{1. $1^{\circ}$ momento: problematização inicial}

Nesse primeiro momento, sugerimos que o professor inicie a aula fazendo um experimento simples, imergindo um lápis em um copo d'água, e logo depois faça um levantamento acerca dos conhecimentos prévios dos alunos, indagando-os com questões como:

- A luz ao bater numa superfície é capaz de atravessála?

- A velocidade de propagação da luz é a mesma qualquer que seja o meio em que se propaga?

- A luz sofre algum desvio ao mudar seu meio de propagação?

- Por que não podemos enxergar o bastão de vidro quando ele fica imerso na glicerina?

Após ouvir as respostas dos alunos, recomendamos que o professor faça uma ampla discussão sobre elas, buscando compreender suas principais concepções a respeito do fenômeno. Assim como na discussão da reflexão, essa etapa permitirá conhecer os conceitos prévios dos alunos e oferecerá subsídios para adequar suas próximas atividades.

A etapa seguinte envolve a experimentação investigativa (EI). Sugerimos dividir a sala em pequenos grupos, fornecendo alguns objetos que os possibilitem investigar o fenômeno da refração, tais como: ponteira laser, transferidores, réguas, lápis, papel, fita adesiva, recipiente transparente, garrafa com água e tinta guache branca ${ }^{14}$ Os alunos devem ser instruídos a elaborar um experimento que indique se o raio de luz desvia ou não durante a refração, e quais as condições para que isso ocorra, utilizando os materiais fornecidos. Por meio de uma folha em branco disponibilizada pelo professor, eles devem explicar a que conclusão chegaram, e como chegaram, através de esquemas e textos. Ao final desse processo, o professor deve recolher a folha. A partir dessa atividade, o professor poderá avaliar se os alunos compreenderam o fenômeno da refração e se eles foram capazes de perceber que o raio de luz desvia a trajetória quando incide obliquamente em um meio refrator.

\subsubsection{Organização do conhecimento}

No segundo momento, o professor deve tecer comentários sobre a aula anterior e sobre os experimentos realizados pelos alunos. Essa atividade tem como propósito fazer com que os alunos organizem seus conhecimentos acerca do fenômeno da refração, baseado nos saberes que já possuem. Em seguida, deve ser iniciada a leitura

\footnotetext{
13 O leitor notará que a estrutura e as frases em boa parte dessa seção são iguais às da anterior. Isso é proposital e indica que o professor é livre para aplicar a proposta na ordem que preferir ou mesmo escolher apenas uma delas.

14 A tinta branca tem como função deixar a água turva e facilitar a visão dos raios de luz.
} 
contextualiza de fontes primárias, começando pelo engajamento: essa explicação para a refração sempre existiu? Com isso, o professor pode verificar o que os alunos já sabem em relação a aspectos históricos da óptica, contribuindo para a tomada de decisões ao longo da aula e eventuais modificações. Posteriormente, na etapa de conhecimentos prévios, o professor deve apresentar alguns dados biográficos e uma síntese das principais obras dos três filósofos naturais protagonistas da proposta: Descartes, Newton e Huygens 15 Posteriormente, na leitura integral, o professor deve distribuir os trechos das fontes primárias, disponíveis nos quadro 3. Após o esclarecimento de eventuais dúvidas em relação aos termos e conceitos dos trechos, a leitura contextualizada pode ter início. Em seguida, na leitura integral, o professor deve distribuir os trechos das fontes primárias, disponíveis nos quadros 5, 6 e 7, fornecendo tempo para leitura. Após o esclarecimento de eventuais dúvidas em relação aos termos e conceitos dos trechos, a leitura contextualizada pode ter início. Conforme descrito na seção 2.3, nesse momento, o professor detalha cada trecho das fontes, a partir dos subsídios elencados nos quadros 5, 6 e 7. Dessa

15 Ver nota 12 maneira, os conteúdos das fontes podem tornar-se mais compreensíveis aos alunos. Também estão disponíveis algumas ilustrações dos autores - as originais e as adaptadas -, que podem ser utilizadas nessa quarta etapa da LC.

O professor deve, após a LC, utilizar os minutos finais da aula para formalizar o entendimento da relação entre as velocidades da luz nos meios de propagação e os ângulos de incidência e refração no viés dos filósofos estudados, atentando-se às peculiaridades de cada modelo e mostrando que mesmo com ideias diferentes, foram capazes de atender a um mesmo propósito. Pretendemos, com isso, construir uma linha de raciocínio que nos permita entender a lei dos senos da refração. É interessante que o professor comente como os autores estudados pensavam a respeito da velocidade de propagação da luz nos diferentes meios como o ar, a água, e o vidro, e explique como eles justificavam a diferença, se por conta da densidade, da dureza do meio, etc.

\subsection{3. $3^{\circ}$ momento: aplicação do conhecimento}

No terceiro momento, o professor deve criar e mediar um debate em sala de aula, para discutir os modelos explicati-

Quadro 5: Subsídios para a leitura contextualizada (LC) - refração - Descartes.

\begin{tabular}{|c|c|}
\hline \multicolumn{2}{|l|}{ Descartes } \\
\hline Dióptrica & \\
\hline Trecho & Subsídios para leitura contextualizada \\
\hline $\begin{array}{l}\text { [...] pensemos que a bola, tendo sido primeiramente impulsionada de A para } \\
B \text {, e ainda uma vez impulsionada, estando no ponto } B \text {, pela raquete CBE que } \\
\text { aumenta a força de seu movimento, por exemplo, de um terço, de modo que ela } \\
\text { possa percorrer depois o mesmo caminho em dois momentos, quando antes ela o } \\
\text { fazia em três. Produzirá o mesmo efeito se ela encontrar no ponto B um corpo } \\
\text { de natureza tal que ela passe, através de sua superfície CBE, um terço mais } \\
\text { facilmente do que pelo ar. } \\
\text { Fonte: }[49, \mathrm{p} .461]\end{array}$ & $\begin{array}{l}\text { Nesse trecho Descartes, ainda fazendo a ana- } \\
\text { logia da bola, como na reflexão, supõe que ao } \\
\text { mudar o meio de propagação, a bola recebe um } \\
\text { novo impulso que aumenta sua rapidez em } 1 / 3, \\
\text { fazendo com que ela seja capaz de percorrer } \\
\text { a mesma distância que antes com tempo } 1 / 3 \\
\text { menor do que antes. }\end{array}$ \\
\hline $\begin{array}{l}\text { Do que já foi demonstrado segue-se evidentemente que, se descrevermos o círculo } \\
\text { AD, como antes, e as linhas } A C, H B, F E \text { de tal modo que haja um terço a menos } \\
\text { de distância entre FE e } H B \text { do que entre } H B \text { e } A C \text {, o ponto } I \text {, onde a linha } \\
\text { reta FE e a circular } A D \text { se interceptam, designará o lugar para o qual essa bola, } \\
\text { estando no ponto } B \text {, deve ser desviada. } \\
\text { Fonte: }[49, \text { p. } 461]\end{array}$ & $\begin{array}{l}\text { Aqui, Descartes prevê para onde ocorrerá o } \\
\text { desvio, argumentando que, como a distância } \\
\text { entre HB e FE é } 1 / 3 \text { menor do que entre HB e } \\
\text { AC, a intersecção entre a direção do movimento } \\
\text { da bola e o círculo traçado ocorrerá em I (Fig. } \\
5) \text {. }\end{array}$ \\
\hline
\end{tabular}

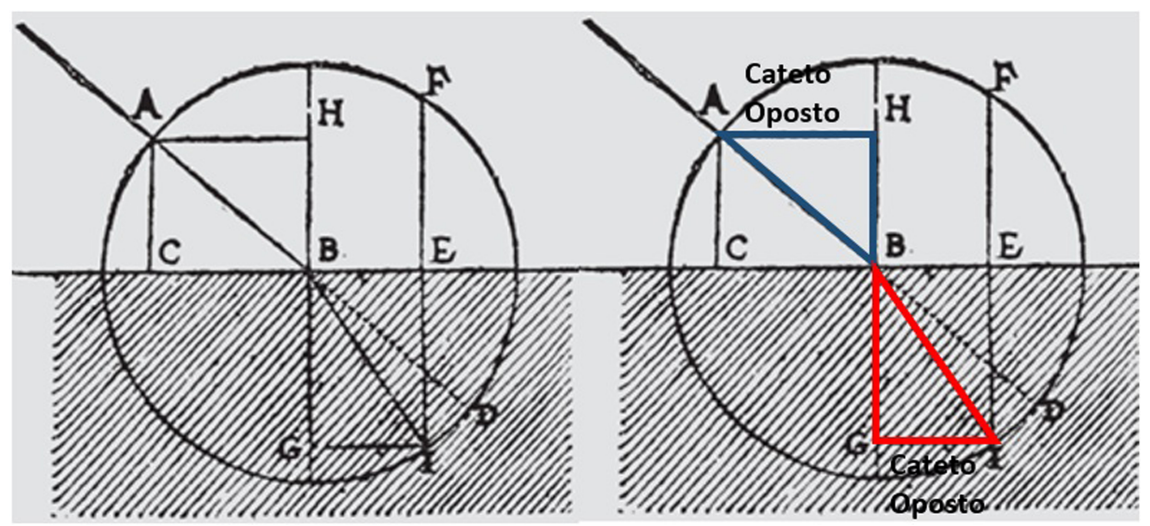

Figura 5: Representação da refração para Descartes. À direita, a figura adaptada indica os triângulos destacados com os ângulos de incidência e reflexão, e seus respectivos senos [49, p. 461]. 
Quadro 6: Subsídios para a leitura contextualizada (LC) - refração - Huygens.

\begin{tabular}{|c|c|}
\hline \multicolumn{2}{|l|}{ Huygens } \\
\hline Tratado sobre a luz & \\
\hline Trecho & Elementos para leitura contextualizada \\
\hline $\begin{array}{l}{[\ldots] \text { seja a reta } A B \text {, que representa uma superfície plana, que limita os corpos }} \\
\text { transparentes que se encontram para } C \text { e para } N[\ldots] \text { que a linha } A C \text { represente } \\
\text { uma parte da onda de luz, cujo centro seja suposto tấo longe que essa parte possa } \\
\text { ser considerada como uma linha reta. } O \text { ponto } C \text { da onda } A C \text {, em um certo } \\
\text { espaço de tempo, terá avançado até o plano } A B, \text { seguindo a reta } C B \text {, que se deve } \\
\text { imaginar proveniente do centro luminoso, e que consequentemente cortará } A C \text { em } \\
\text { ângulos retos. Ora, ao mesmo tempo, o ponto } A \text { teria chegado a } G \text { pela reta } A G \text {, } \\
\text { igual a paralela a } C B \text {, e toda a parte da onda AC estaria em } G B \text {, se a matéria do } \\
\text { corpo transparente transmitisse o movimento da onda tão depressa quanto o éter. } \\
\text { Fonte: }[25, \text { p. } 33]\end{array}$ & $\begin{array}{l}\text { Nesse primeiro momento, Huygens pede que, } \\
\text { assim como na reflexão, o leitor pense em uma } \\
\text { onda com centro tão distante que possa ser } \\
\text { considerada uma linha reta AC, e então diz } \\
\text { que AC chegaria em GB caso o meio transpa- } \\
\text { rente transmitisse o movimento da onda com } \\
\text { a mesma rapidez que o ar. }\end{array}$ \\
\hline $\begin{array}{l}\text { Mas suponhamos que ele transmite esse movimento menos velozmente, por exemplo, } \\
\text { de um terço. O movimento terá portanto se espalhado desde o ponto A, na matéria } \\
\text { do corpo transparente, por uma distância igual a dois terços de CB, fazendo } \\
\text { sua onda esférica particular, segundo o que foi dito antes. Essa onda é portanto } \\
\text { representada pela circunferência SNR, cujo centro é A, e seu semidiâmetro é } \\
\text { igual a } 2 / 3 \text { de CB. Se considerarmos depois os outros pontos } H \text { da onda AC, } \\
\text { aparecerá que ao mesmo tempo em que o ponto } C \text { chegou a B, eles não somente } \\
\text { terão chegado à superfície AB, por retas HK paralelas a CB, mas além disso terão } \\
\text { gerado, dos centros } K \text {, ondas particulares no [corpo] diáfano, representadas aqui } \\
\text { por circunferências cujos semidiâmetros sâo iguais a } 2 / 3 \text { das linhas KM, quer } \\
\text { dizer, aos } 2 / 3 \text { das continuaçoses de HK até a reta } B G \text {; pois esses semidiâmetros }\end{array}$ & $\begin{array}{l}\text { Aqui, Huygens supõe que a onda AC irá pertur- } \\
\text { bar o meio transparente no qual irá penetrar, } \\
\text { gerando em cada ponto em que toca uma nova } \\
\text { onda esférica particular, assim como foi visto } \\
\text { na reflexão. No entanto, esse meio deve reduzir } \\
\text { de } 1 / 3 \text { a sua velocidade fazendo com que a } \\
\text { distância AN (raio da circunferência SNR com } \\
\text { centro no ponto A) seja igual a } 2 / 3 \text { da reta CB, } \\
\text { assim como todos os pontos K gerarão ondas } \\
\text { esféricas particulares e seus raios equivalerão a } \\
2 / 3 \text { das retas KM (Fig. } 6 \text { ). }\end{array}$ \\
\hline
\end{tabular}
teriam sido iguais aos KM inteiros, se os dois [corpos] diáfanos fossem da mesma penetrabilidade.

Fonte: [25, p. 34]
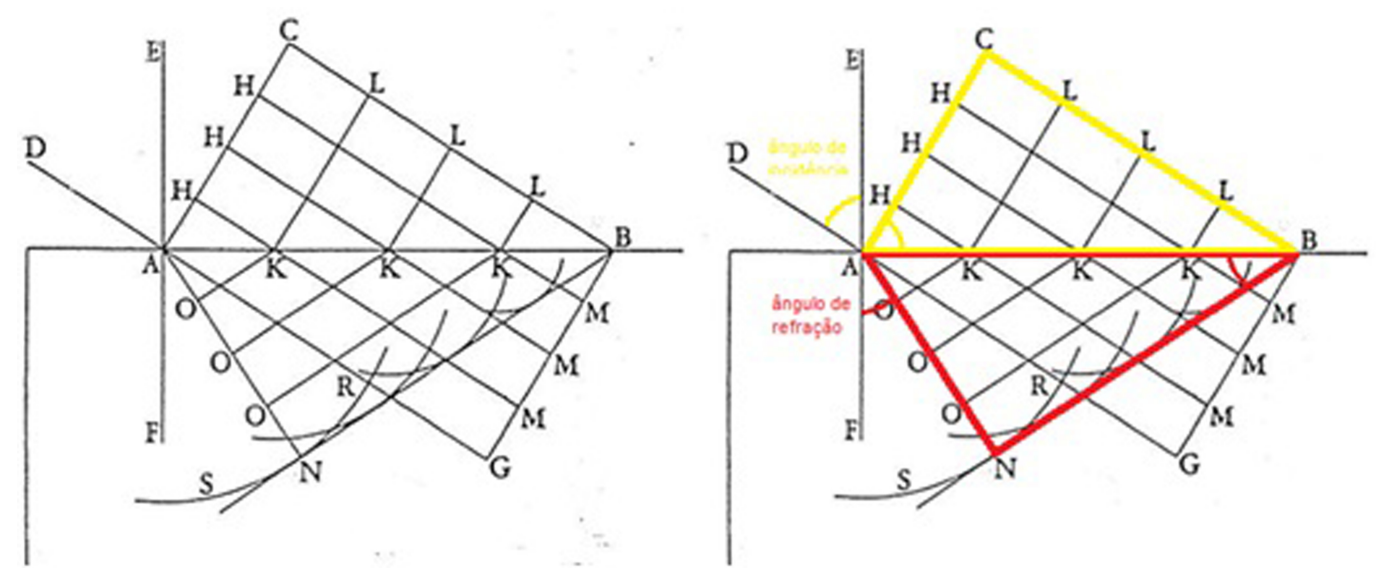

Figura 6: Representação da refração para Huygens. À direita, a figura adaptada indica os triângulos destacados com os ângulos de incidência e reflexão, e seus respectivos senos [25, p. 33].

vos estudados na aula anterior, levando em consideração a importância que cada um deles teve no processo de construção do conhecimento científico. O intuito desse momento é reforçar a discussão da última etapa da LC, trabalhando sobre os aspectos da NdC descritos anteriormente: a contínua transformação do conhecimento científico e a impossibilidade de um modelo científico ser o único modo de explicar um fenômeno.

Podemos iniciar a discussão com a questão: é possível que um modelo científico forneça a única interpretação possível sobre um fenômeno? Por exemplo, Newton propôs que a luz se propagava mais rapidamente em meios mais densos. Huygens, por outro lado, estabeleceu que a velocidade de propagação da luz era menor em meios mais densos, conforme é aceito atualmente. Mesmo com essas divergências, seus modelos conseguiram explicar a refração e demonstrar sua lei, o que indica que a explicação de um fenômeno não é exclusiva de um único modelo.

Outro pronto que podemos tomar como exemplo é a forma como Descartes elabora seu modelo. Mesmo descartando a materialidade da luz, ele utiliza o exemplo de um corpo sólido sofrendo refração para construir sua teoria de refração, e faz isso como se não houvesse distinção entre a refração de um pulso de luz e um corpo sólido. Segundo Shapiro [19], Descartes nunca fez menção ou sequer compreendeu que pudesse haver essa diferença. Isso pode ser útil para trabalhar a ideia de que os modelos podem ter aspectos, a princípio, contraditórios, mas que não são vistos dessa maneira pelos seus idealizadores. 
Quadro 7: Subsídios para a leitura contextualizada (LC) - refração - Newton.

\begin{tabular}{|c|c|}
\hline \multicolumn{2}{|l|}{ Newton } \\
\hline Óptica & \\
\hline Trecho & Elementos para leitura contextualizada \\
\hline $\begin{array}{l}\text { Definição IV } \\
\text { Ângulo de incidência é o ângulo em que a reta descrita pelo raio incidente forma } \\
\text { com a perpendicular à superfície refletora ou refratora no ponto de incidência. } \\
\text { Definição V } \\
\text { Ângulo de reflexão ou refração é o ângulo em que a reta descrita pelo raio refletido } \\
\text { ou refratado forma com a perpendicular à superfície refletora ou refratora no } \\
\text { ponto de incidência. }\end{array}$ & $\begin{array}{l}\text { Aqui, Newton define de maneira clara e obje- } \\
\text { tiva que o ângulo que o raio incidente forma } \\
\text { com a perpendicular é chamado de ângulo de } \\
\text { incidência, e o que o de refração forma com a } \\
\text { perpendicular é chamado de ângulo de refração } \\
\text { (Fig. 7). }\end{array}$ \\
\hline
\end{tabular}

\title{
Proposição 9
}

Os corpos refletem e refratam a luz em virtude de uma mesma força, exercida variadamente em várias circunstâncias.

Fonte: [51, p. 203]

\begin{abstract}
Proposição 10
Se a luz for mais veloz nos corpos do que no vácuo, na proporção dos senos que medem a refração dos corpos, as forças dos corpos para refletir e refratar a luz serão muito aproximadamente proporcionais às densidades dos mesmos corpos, exceto que os corpos oleosos e sulfurosos refratam mais do que outros da mesma densidade.

Seja $A B$ a superfície plana refratora de qualquer corpo e IC um raio que incide muito obliquamente sobre o corpo em $C$, de forma que o ângulo ACI possa ser infinitamente pequeno, e seja $C R$ o raio refratado.

[...] se CR representa o movimento do raio refratado, e esse movimento for dividido em dois movimentos $C B$ e BR, dos quais $C B$ é paralelo ao plano refrator e $B R$ perpendicular a ele, $C B$ representará o movimento do raio incidente e $B R$ o movimento gerado pela refração, como os ópticos tem explicado ultimamente.
\end{abstract}

Fonte: [51, p. 204]

\begin{abstract}
Proposição 10 (cont.)
Ora, se qualquer corpo ou coisa, movendo-se através de um espaço qualquer de uma dada extensão e terminado em ambos os lados por dois planos paralelos, for estimulado para frente em todas as partes desse espaço por forças que tendam diretamente para frente em direção ao último plano e que, antes de sua incidência no primeiro plano, não tinha nenhum movimento em direção a ele, ou tinha apenas um movimento infinitamente pequeno; e se as forças existentes em todas as partes desse espaço entre os planos forem iguais umas às outras a distâncias iguais dos planos, mas a distâncias diversas forem maiores ou menores em qualquer proporção dada, o movimento gerado pelas forças na passagem completa do corpo ou coisa através do espaço estará numa proporção subduplicada das forças, como os matemáticos entenderam facilmente.

$[\ldots]$

Portanto, se no espaço de atividade da superfície refratora do corpo for considerado como tal espaço, o movimento do raio gerado pela força refratora do corpo durante sua passagem através desse espaço (isto é, o movimento BR) deve estar numa proporção subduplicada dessa força refratora. Digo, portanto, que o quadrado da linha BR, e por consequência a força refratora do corpo, é muito aproximadamente proporcional à densidade do mesmo corpo.
\end{abstract}

Fonte: [51, p. 204-205]

Newton, por exemplo, utilizou variados modelos para tentar justificar a reflexão e a refração da luz. Em um primeiro momento, ele não se preocupou em justificar as causas do fenômeno, adotando a postura da obviedade retirada da experimentação. Posteriormente, pensou em um modelo de força entre a luz e a matéria, que poderia atuar tanto na reflexão quanto na refração. Essa teoria foi construída de forma semelhante ao que ele fez em seu Principia, ao estudar a reflexão e a refração de um corpo sólido.

Após esse debate, deve ser proposta uma atividade final para os alunos aplicarem o conhecimento. Segue um exemplo de atividade.
Neste trecho, Newton atribuiu como causa da reflexão e da refração a uma força que exercida pelo material refletor/refrator.

Nesta proposição, Newton afirma que quando a luz se move mais rápido nos corpos do que no vácuo, a força que está relacionada com a refração é proporcional à densidade do corpo. Nos trechos seguintes, Newton explica a figura 09 , na qual temos um raio que incide no ponto $\mathrm{C}$ e é refratado até o ponto $\mathrm{R}$. Segundo a descrição, esse raio incidente forma um ângulo tão pequeno com a reta normal que é praticamente paralelo à linha $\mathrm{AB}$ (Fig. 8).

Neste trecho, Newton diz que quando o raio incide quase que paralelamente à linha $\mathrm{AB}$, praticamente todo o movimento perpendicular que esse raio adquire (direção de BR) vem da ação da força refratora, estimulando-o para frente, no sentido de B para R. E ele afirma que após a passagem completa do raio, sofrendo a ação dessa força que age em todas as partes do material, a velocidade adquirida na direção perpendicular será proporcional à raiz quadrada da força refratora. $\underline{\text { Atividade final }}$

1. Responda as questões:

a) Descreva resumidamente como Descartes, Huygens e Newton explicam a refração da luz. Dê bastante ênfase à geometria utilizada por cada um deles.

b) Olhando para os três modelos, é possível perceber que o conhecimento científico não é estático e nem convergente? Explique.

2. Uma das formas de escrever a lei da refração é mostrada a seguir: 

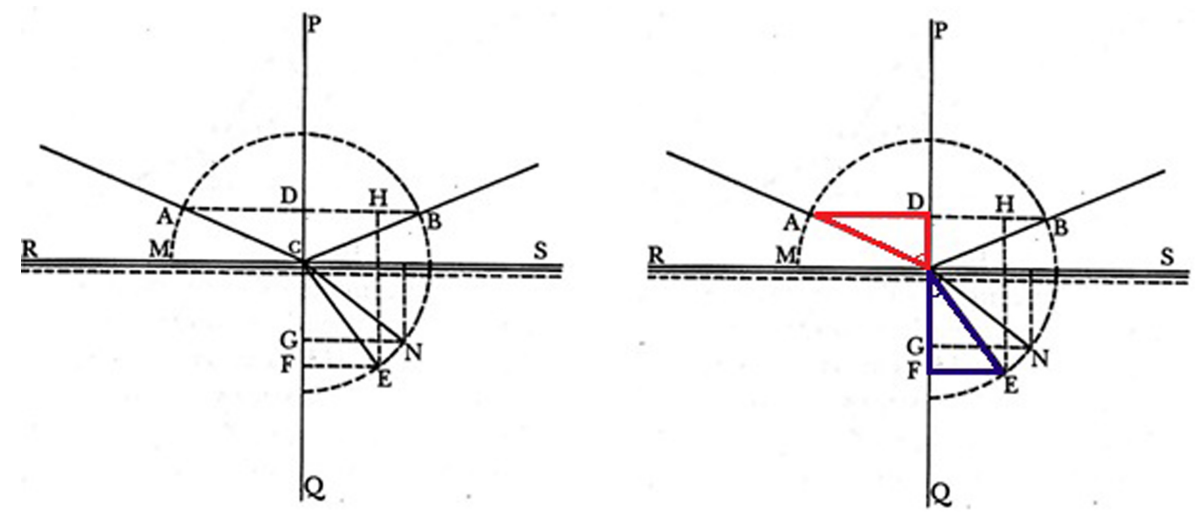

Figura 7: Representação da refração para Newton. À direita, a figura adaptada indica os triângulos destacados com os ângulos de incidência e reflexão, e seus respectivos senos [51, p. 43].
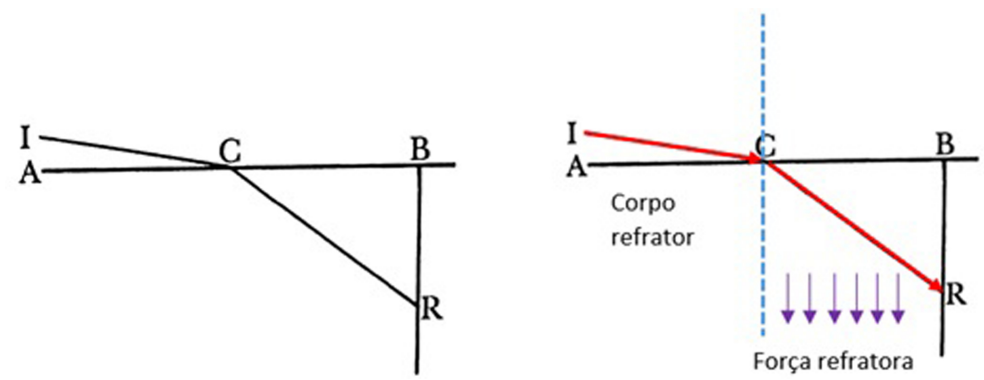

Figura 8: Representação de um raio sofrendo refração. À direita, a figura adaptada indica a direção dos raios e a ação da força refratora [51, p. 204].

$$
\frac{\operatorname{sen} \theta_{\text {incidência }}}{\operatorname{sen} \theta_{\text {refração }}}=\frac{v_{\text {meio } 1}}{v_{\text {meio } 2}}
$$

Pesquise, construa um experimento e calcule a velocidade de propagação da luz na água. Se necessário, utilize: $\mathrm{v}_{\mathrm{ar}}=3.10^{8} \mathrm{~m} / \mathrm{s}$.

\section{Considerações finais}

Nas seções precedentes, discutimos uma proposta de abordagem alternativa às tradicionais para tornar um curso de óptica geométrica mais interessante para o aluno, menos carregado de formalismo geométrico, símbolos e equações. Para tal, utilizamos diversos pilares, que vão desde a história da ciência até questões próprias do ensino e aprendizagem. Entendemos que essa proposta pode contemplar os desejos atuais de fomentar uma educação mais crítica e dinâmica. A estrutura apresentada para a proposta permite sua utilização de modo diverso, de acordo com os caminhos percorridos pelo professor em sala de aula. Acreditamos que, dessa maneira, é viável, por um lado, estudar dois fenômenos básicos da óptica de forma mais engajadora e, por outro, oferecer aporte histórico adequado para compreender questões da natureza do conhecimento científico, desde aspectos teóricos até práticos. Assim, a óptica hoje relegada a poucas páginas dos manuais escolares e a uma abordagem excessivamente superficial pode ter, enfim, um tratamento mais próximo de sua importância para a física e para sua história.

\section{Referências}

[1] M.R. Matthews, Science Teaching - The Role of History and Philosophy of Science (Routhledge, New York, 1994).

[2] L.O.Q. Peduzzi, in: Ensino de Física: conteúdo, metodologia e epistemologia numa concepção integradora, editado por M. Pietrocola (Editora da UFSC, Florianópolis, 2001)

[3] D. Allchin, Teaching the nature of science: perspectives and resources (SHiPS Education Press, Saint Paul, 2013).

[4] B.A. Moura, Revista Brasileira de História da Ciência 7, 32 (2014).

[5] D. Höttecke e C.C. Silva, Science \& Education 20, 293 (2011).

[6] T.C.M. Forato, R.A. Martins e M. Pietrocola, Science \& Education 21, 657 (2012).

[7] B.A. Moura e C.C. Silva, Revista Brasileira de História da Ciência 7, 336 (2014).

[8] O. Darrigol, A history of optics from Greek Antiquity to the Nineteenth Century (Oxford University Press, Oxford, 2012).

[9] L.H. Sasseron, Revista Brasileira de Pesquisa em Educação em Ciências 18, 761 (2018).

[10] D. Delizoicov, Concepção problematizadora do ensino de ciências na educação formal: relato e análise de uma prática educacional na Guiné Bissau. Dissertação de Mestrado, Universidade de São Paulo, São Paulo (1982). 
[11] B.A. Moura, in: Objetivos humanísticos, conteúdos científicos: contribuições da história e da filosofia da ciência para o ensino de ciências (EdUEPB, Campina Grande, no prelo).

[12] D.C. Ortega, Uma abordagem histórica da propagação, reflexão e refração da luz. Dissertação de mestrado, Universidade Federal do ABC, Santo André (2018).

[13] J.P. Gircoreano e J.L. Pacca, Caderno Catarinense de Ensino de Física 18, 26 (2001).

[14] L.C. Menezes, in: Fúsica ainda é cultura?, editado por A.F.P. Martins (Editora Livraria da Física, São Paulo, 2009).

[15] K.B. Albuquerque, P.J.S. Santos e G.K. Ferreira, Caderno Brasileiro de Ensino de Física 32, 461 (2015).

[16] B.A. Moura, Caderno Brasileiro de Ensino de Física 33, 111 (2016).

[17] G.N. Cantor, Optics after Newton - theories of light in Britain and Ireland, 1704-1840 (Manchester University Press, Manchester, 1983).

[18] C. Hakfoort, Optics in the age of Euler - conceptions of the nature of light, 1700-1795 (Cambridge University Press, Cambridge, 1995).

[19] A.E. Shapiro, Archive for History of Exact Sciences 11, 134 (1973).

[20] A.I. Sabra, Theories of light from Descartes to Newton. (Cambridge University Press, Cambridge, 1981).

[21] S. Krapas, G.R.P.C. Queiroz e D. Uzêda, Caderno Brasileiro de Ensino de Física 28, 123 (2011).

[22] R.A. Martins e C.C. Silva, Revista Brasileira de Ensino de Física 37, 4202 (2015).

[23] J.P.S. Ramos, Scientiae Studia 8, 421 (2010).

[24] A.W. Badcock, The British Journal for the History of Science 1, 99 (1962)

[25] C. Huygens, Caderno de História e Filosofia da Ciência supl.4, 11 (1986).

[26] A.R. Hall, All was light: an introduction to Newton's "Opticks" (Claredon Press, Oxford, 1993), p. 20.

[27] I. Newton, in: Newton: textos, antecedentes, comentários, editado por I.B. Cohen e R. Westfall (EdUerj Contraponto, Rio de Janeiro, 2002), p. 28.

[28] A.E. Shapiro, in: The Cambridge Companion to Newton, editado por I.B. Cohen e G.E. Smith (Cambridge University Press, Cambridge, 2002).

[29] C.C. Silva e R.A. Martins, Revista Brasileira de Ensino de Física 18, 313 (1996).

[30] M.A. Moreira, Estudos Avançados 32, 73 (2018).

[31] A.M.P. Carvalho, A.I. Vannucchi, M.A. Barros, M.E.R. Gonçalves e R.C. Rey, Ciências no Ensino Fundamental: o conhecimento físico (Scipione, São Paulo, 1998).

[32] S.S. Guedes, Experimentação no ensino de ciências: atividades problematizadas e interações dialógicas. Dissertação de mestrado, Universidade de Brasília, Brasília (2010).

[33] W.E. Francisco Júnior, Revista Química Nova na Escola 29,20 (2008).

[34] P. Freire, Pedagogia do Oprimido. (Paz e Terra, São Paulo, 1996).

[35] N. Barrelo Júnior, Argumentação no discurso oral e escrito de alunos do ensino médio em uma sequência didática de Física Moderna. Dissertação de Mestrado, Universidade de São Paulo, São Paulo (2010).
[36] E.S. Lopes, E o Elétron? É Onda ou é Partícula? - Uma proposta para promover a ocorrência da alfabetização científica de física moderna e contemporânea em estudantes do ensino médio. Dissertação de Mestrado, Universidade de São Paulo, São Paulo (2013).

[37] L.H. Sasseron e A.M.P. Carvalho, Investigações em Ensino de Ciências 16, 59 (2011).

[38] M.R. Matthews, Caderno Catarinense de Ensino de Física 12, 164 (1995).

[39] B.A. Moura, in: Objetivos humanísticos, conteúdos científicos: contribuições da história e da filosofia da ciência para o ensino de ciências, editado por A.P.B. da Silva e B.A. Moura (EdUEPB, Campina Grande, 2019).

[40] T.C.M. Forato, A natureza da ciência como saber escolar: um estudo de caso a partir da história da luz. Tese de Doutorado, Universidade de São Paulo, São Paulo (2009).

[41] S.L.B. Boss, Tradução comentada de artigos de Stephen Gray (1666-1736) e reprodução de experimentos históricos com materiais de baixo custo - subsídios para o ensino de eletricidade. Tese de Doutorado, Universidade Estadual Paulista, São Paulo (2011).

[42] G.L.F. Batista, J.M.H.F. Drummond e D.B. Freitas, Caderno Brasileiro de Ensino de Física 32, 663 (2015).

[43] W.F. McComas, H. Almazroa e M.P. Clough, Science 86 Education 7, 511 (1998).

[44] S. Pumfrey, British Journal for the History of Science 24, 61(1991).

[45] D. Gil-Pérez, Enseñanza de las Ciencias 11, 197 (1993).

[46] N.G. Lederman, in: Handbook of research in Science Education, editado por S. Abell e N.G. Lederman (Routledge, New York, 2007), p. 831-879.

[47] G.R. Silva, Revista Brasileira de História da Ciência 6, 121 (2013).

[48] R.O. Borges e H.P.S. Corrêa, Ciências em Foco 10, 3 (2017).

[49] R. Descartes, Scientiæ studia 8, 451 (2010).

[50] I. Newton, Principia (Edusp, São Paulo, 2016).

[51] I. Newton, Óptica (Edusp, São Paulo, 1996). 